Original Research Paper

\title{
Using of Box-Benken Method to Predict the Compressive Strength of Self-Compacting Concrete Containing Wadi Musa Bentonite, Jordan
}

\author{
Arabi N.S. AL Qadi, Mahmoud B.A. ALhasanat, Ahmad AL Dahamsheh and Sleiman AL Zaiydneen \\ Department of Civil Engineering, AL Hussien Bin Talal University, Ma'an, Box 20, Jordan
}

Article history

Received: 28-04-2016

Revised: 22-05-2016

Accepted: 26-05-2016

Corresponding Author:

Arabi N.S. Al Qadi

Department of Civil

Engineering, AL Hussien Bin

Talal University, Ma'an, Box

20, Jordan

Email: arabi@ahu.edu.jo

\begin{abstract}
This research presents application of Box-benken design method to develop model for predicting 28 days compressive strength of SelfCompacting Concrete (SCC) with partial replacement of cement with Wadi Musa bentonite, Jordan for which the data of 15 mixtureshave been tested and preparedat the laboratory of AL Hussien Bin Talal University. The use of Bentonite as filler materials in self-compacting concrete can add many benefits that are directly related to the durability of various cementitious materials, besides the fact that it is possible to reduce the quantities of cement and optimize the percentage in the composite. The performance of the model can be judged by the correlation coefficient (R2), Mean Absolute Error (MAE) and root Mean Square Error (MSE) have been adopted as the comparative measures against the experimental results obtained from the mixtures and found the best percentage of Bentonite in SCC.
\end{abstract}

Keywords: Box-Benken Method, Wadi Musa Bentonite, Self-Compacting Concrete, Compressive Strength, Partial Replacement

\section{Introduction}

Self-Compacted Concrete (SCC) has been described as "the most revolutionary development in concrete construction for several decades" (EFNARC, 2002). It is an innovative concrete that does not require vibration for placing and compaction. It is able to flow under its own weight, completely filling formwork and achieving full compaction, even in the presence of congested reinforcement. It was first introduced by Japanese researchers in the late 1980 's. Due to the high quality and positive environmental impact development of such concrete is required. In normal concrete and also SCC, fillers are used for quality and financial purposes (Alhasanat et al., 2016). Jordanian Bentonite which is a clay material is studied as filler in a set of SCC mixes and with different percentages to indicate it is effect on hardened properties of SCC. Box-behnken design of experiment approach is used along the way to analyze, interpret and modeling of the results.

Bentonite is an absorbent aluminum phyllo silicate, essentially impure clay consisting mostly of montmorillonite. The absorbent clay was given the name bentonite by Wilbur C. Knight in 1898, after the Cretaceous Benton Shale near Rock River,
Wyoming. Bentonite usually forms from weathering of volcanic ash, most often in the presence of water. However, the term bentonite, as well as similar clay called tonstein, has been used to describe clay beds of uncertain origin. For industrial purposes, two main classes of bentonite exist: Sodium and calcium Bentonite (Hosterman and Patterson, 1992).

The developed of SCC by using contrast constant factorial design to determine if adjustment of the four factors viz. cement content (C), water to powder (w/p) ratio, Fly Ash (FA) content and Super-Plasticizer (SP) will increase the compressive strength of SelfCompacting Concrete (SCC) by using contrast constant factorial design and response surface methodology. They concluded that to maximize the compressive strength, variables like cement content, water to powder ratio, fly ash content and super plasticizer dosage, should be kept at a high level and the process is relatively robust to content of super-plasticizer. The highest compressive strength is obtained when cement contents, w/p, FA contents are high and SP is low (Al Qadi et al., 2013).

Long et al. (2015) modeled effect of mixture parameters and material properties on the hardened properties of, prestressed Self-Compacting Concrete 
(SCC) and also to investigate the extensions of the statistical models, a factorial design was employed to identify the relative significance of these primary parameters and their interactions in terms of the mechanical and visco-elastic properties of SCC. In addition to the 16 fractional factorial mixtures evaluated in the modeled region of -1 to +1 , eight axial mixtures were prepared at extreme values of -2 and +2 with the other variables maintained at the central points. Four replicate central mixtures were also evaluated. The effects of five mixture parameters, including binder type, binder content, dosage of Viscosity-Modifying Admixture (VMA), water-cementitious material ratio $(\mathrm{w} / \mathrm{cm})$ and sand-to-total aggregate ratio $(\mathrm{S} / \mathrm{A})$ on compressive strength, modulus of elasticity, as well as autogenous and drying shrinkage are discussed. The applications of the models to better understand tradeoffs between mixture parameters and carry out comparisons among various responses are also highlighted. A logical design approach would be to use the existing model to predict the optimal design and then run selected tests to quantify the influence of the new binder on the model (Long et al., 2015).

Fillers in general aim to enhance quality or lowering the cost of concrete mixes, such reasons made the engineering community look forward to discover new fillers that are reliable and efficient to be used and thus it is important to support this field with research and development in order to produce SCC that can be used efficiently, safely and reliably.

The objective of this research is to study the effect of addition Bentonite on self- compacted concrete properties such as compressive strength and durability for hardened properties.

\section{Methodology}

\section{Material Used}

Cement: Ordinary Portland cement of available in local market is used in the investigation. The cement used has been tested various proportions as per (ASTM C150-85A) the specific gravity was 3.15 and fineness was $2091 \mathrm{~cm}^{2} \mathrm{gm}^{-1}$.

Coarse aggregate: Crushed angular granite material of $20 \mathrm{~mm}$ max size from a local source will be used as coarse aggregate. The specific gravity of 2.45 , absorption value was $2 \%$, fineness modulus 6.05 and bulk density of $1480 \mathrm{~kg}$ per $\mathrm{m}^{3}$ confirms to ASTM C 33-86 will be used.

Fine aggregate: The fine aggregate consisted of river sand with maximum size of $4.75 \mathrm{~mm}$ with a modulus of fineness 4.16; normal grading with a Specific gravity of 2.33 and absorption of $11 \%$.

Bentonite: Sodium Bentonite sample taken from Ma`an-WadiMousa and sieved through sieve no. 200 and showed the following chemical and physical properties were shown in Table 1.

Super plasticizer: Polycarpoxylicether (PCE) based super-plasticizer which is brown color and free flowing liquid and having relative density 1.15 super plasticizer confirms to ASTM C 494-92 type A is used.

Mixing water: Potable water confirms to ASTM D 11297 for mixing the concrete and curing of the reaction.

\section{Box-Banken Approach}

Design of Experiment (DOE) approach were used in this study and the reason why DOE is used is that because it offers lesser number of Representative samples, the ability of analyzing and interpret, controlling and organizing the research and the reason why the Box-Behnken method specifically was used is because it's convenient for engineering application (Jmp software Manuel. version 12).

In statistics, Box-Behnken designare experimental design for response surface methodology, devised by George E. P. Box and Donald Behnken in 1960, to achieve the following goals:

Each factor, or independent variable, is placed at one of three equally spaced values, usually coded as $-1,0$, +1 . (At least three levels are needed for the following goal.) The design should be sufficient to fit a quadratic model, that is, one containing squared terms and products of two factors. The ratio of the number of experimental points to the number of coefficients in the quadratic model should be reasonable (in fact, their designs kept it in the range of 1.5 to 2.6). The estimation variance should more or less depend only on the distance from the centre (this is achieved exactly for the designs with 4 and 7 factors) and should not vary too much inside the smallest (hyper) cube containing the experimental points. About 15 mixes with different ratios for each were casted to fulfill the requirements of the design of experiment conducted.

Mixture preparation: Each mix of these 15 mixes was subjected to hardened properties tests. Cubes were casted with material proportions for compressive strength test and beam casted with material proportions if flexure strength test were to be conducted as shown in Table 2 .

Hardened Properties: Hardened properties of SCC tests of compressive strength are required for one or both of the following purposes: To check the potential strength of the concrete under controlled conditions against the desired strength; and. To establish a strength-age relationship for the concrete under job conditions as a control for construction operations or the opening of the work.

The compressive strength tests of the specimens were conducted according to ASTM C39-11. For each mix, cube of size $15 \times 15 \times 15 \mathrm{~cm}$ were prepared and three specimens of each mix were tested at the ages of 28 days to determine the average compressive strength. 
Table 1. Chemical and physical properties of Bentonite

\begin{tabular}{lclr}
\hline & Bentonite & & \\
Chemical symbols (\%) & Wadi-Mousa (\%) & Physical properties & 2.59 \\
$\mathrm{Na}_{2} \mathrm{O}$ & 0.13 & Specific gravity & 410.00 \\
$\mathrm{MgO}$ & 3.47 & Specific surface area (m²/g) & 65.00 \\
$\mathrm{Al}_{2} \mathrm{O}_{3}$ & 20.08 & CEC Meq 1100 g & 80.00 \\
$\mathrm{SiO}_{2}$ & 55.67 & Oil absorption (\%) by wt & 207.00 \\
$\mathrm{~K}_{2} \mathrm{O}$ & 2.45 & Water absorption (\%) by wt & 90.00 \\
$\mathrm{CaO}$ & 2.15 & Attrition resistance \% & 13.00 \\
$\mathrm{TiO}_{2}$ & 2.54 & Adsorption of water vapor \% & 89.00 \\
$\mathrm{Fe}_{2} \mathrm{O}_{3}$ & 13.47 & Bleaching capacity of edible oil (\%) & \\
\end{tabular}

Table 2. Mixtures proportions and compressive strength of SCC

\begin{tabular}{lllllllll}
\hline $\begin{array}{l}\text { Mixture } \\
\text { No. }\end{array}$ & $\begin{array}{l}\text { Cement } \\
\left(\mathrm{Kg} / \mathrm{m}^{3}\right)\end{array}$ & $\begin{array}{l}\text { W/P } \\
\text { Ratio }\end{array}$ & $\begin{array}{c}\text { Bentonite } \\
(\%)\end{array}$ & $\begin{array}{l}\text { Water } \\
\left(\mathrm{Kg} / \mathrm{m}^{3}\right)\end{array}$ & $\begin{array}{l}\text { Super- } \\
\text { Plasticizer } \\
\left(\mathrm{Kg} / \mathrm{m}^{3}\right)\end{array}$ & $\begin{array}{l}\text { Coarse } \\
\text { Aggregate } \\
\left(\mathrm{Kg} / \mathrm{m}^{3}\right)\end{array}$ & $\begin{array}{l}\text { Fine } \\
\text { Aggregate } \\
\left(\mathrm{Kg} / \mathrm{m}^{3}\right)\end{array}$ & $\begin{array}{l}\text { Compressive } \\
\text { Strength } \\
(\mathrm{MPa})\end{array}$ \\
\hline 1 & 450 & 0.375 & 5.0 & 177.2 & 9 & 1042.4 & 669.2 & 36.6 \\
2 & 400 & 0.450 & 20.0 & 216.0 & 8 & 970.9 & 623.3 & 19.5 \\
3 & 350 & 0.450 & 12.5 & 177.2 & 7 & 1083.4 & 695.5 & 30.7 \\
4 & 350 & 0.375 & 5.0 & 137.8 & 7 & 1163.6 & 747.0 & 24.0 \\
5 & 450 & 0.300 & 20.0 & 151.9 & 9 & 1062.4 & 682.0 & 38.5 \\
6 & 350 & 0.300 & 12.5 & 118.1 & 7 & 1179.1 & 757.0 & 27.0 \\
7 & 400 & 0.450 & 5.0 & 189.0 & 8 & 1052.0 & 675.3 & 29.0 \\
8 & 450 & 0.375 & 20.0 & 202.5 & 9 & 959.4 & 615.9 & 46.0 \\
9 & 450 & 0.450 & 12.5 & 227.8 & 9 & 939.4 & 603.0 & 49.0 \\
10 & 400 & 0.375 & 12.5 & 168.8 & 8 & 1066.1 & 684.4 & 25.0 \\
11 & 400 & 0.375 & 12.5 & 168.8 & 8 & 1066.1 & 684.4 & 25.0 \\
12 & 400 & 0.375 & 12.5 & 168.8 & 8 & 1066.1 & 684.4 & 25.0 \\
13 & 400 & 0.300 & 20.0 & 144.0 & 8 & 1087.5 & 698.1 & 39.3 \\
14 & 400 & 0.300 & 5.0 & 126.0 & 8 & 1154.0 & 740.9 & 36.8 \\
15 & 350 & 0.375 & 20.0 & 157.5 & 7 & 1099.0 & 705.5 & 29.4 \\
\hline
\end{tabular}

\section{Results and Discussion}

Results obtained from testing the mixes behavior and properties will be discussed in the light of the design of experiment predictions and the ASTM and EFNARC guide. For each test results will be shown followed by a scientific and engineering discussion, Measurements and data that were recorded in the laboratory were collected, analyzed and studied. In the lack of a complete standard for designing a SCC mix, interpretation of results will be according to the ASTM and EFNARC standard. The use of each guide was depended on the situation and atmosphere of each experiment as shown in Table 2.

Figure 1 shows the predicted compressive strength versus the actual compressive strength obtained for $5 \%$ Bentonite. The compressive strength of mixes will be examined and discussed in detail for the purpose of understanding the effect of bentonite on the compressive strength of the mixes. Statistical parameters for the purpose of DOE modeling and predictions will be followed through Fig. 1 and Table 3 and 4.

ANOVA for full quadratic models are shown in Table 4. The lacks of fits were tested for full quadratic models. The $\mathrm{p}$-values for this test is low in $\mathrm{fc}_{28}$ which is
0.0199 suggested that there is no lack of fit. The F statistical tests for significance of regression is 7.4314 and 0.0199 since the p-value with small value indicate that, the Ho: $\alpha 1, \alpha 2, \alpha 3, \alpha 4=0$ is rejected and accepted in $\mathrm{fc}_{28}$, concluding that at least some of the parameters are non-zero. This mean that the linear and square terms contribute significantly to the model and the contribution of the interaction terms are not quite significant. The residual error 79.5075 and the pure error 0 not that much difference so there is a lack of fit. The ANOVA test suggests that the full quadratic model adequately describe the $\mathrm{fc}_{28}$ data.

Figure 2 below indicates that the effect of each parameter when interacting with other parameters and the effect that it has on it is own. Bentonite showed a log worth of 0.816 as a parameter affects the response when quantity is changed.

Red lines in Fig. 2 represent the compressive strength response for $5 \%$ off bentonite replacing cement. For 5\% of bentonite mixes the maximum compressive strength that can be reached is $36 \mathrm{Mpa}$ and that can be obtained by mixing materials that coordinates with the red line above in Fig. $2\left(400-450 \mathrm{~kg} / \mathrm{m}^{3}\right)$ of cement and a w/p ratio (0.30-0.375). 


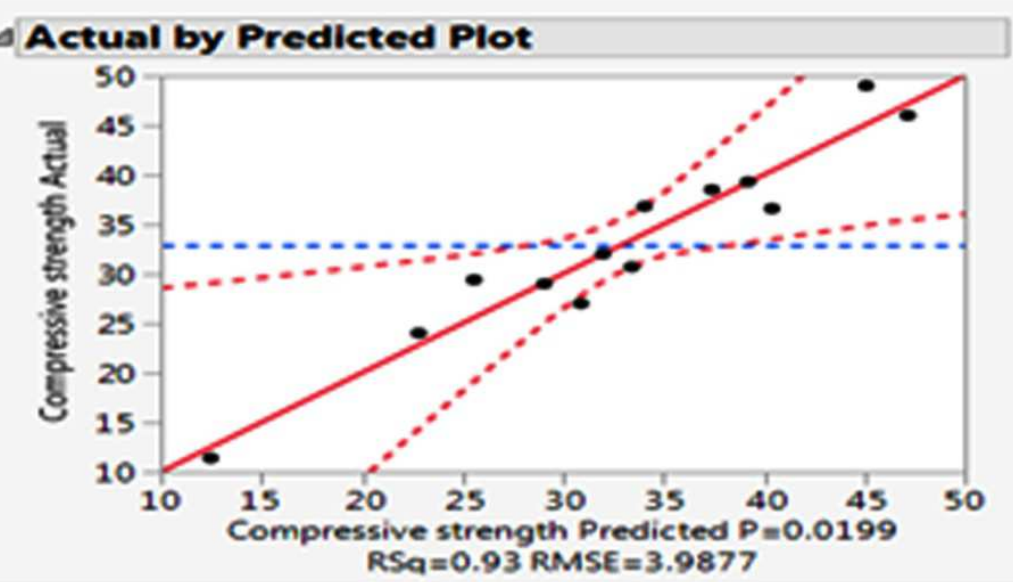

Fig. 1. Compressive strength actual by predicted plot

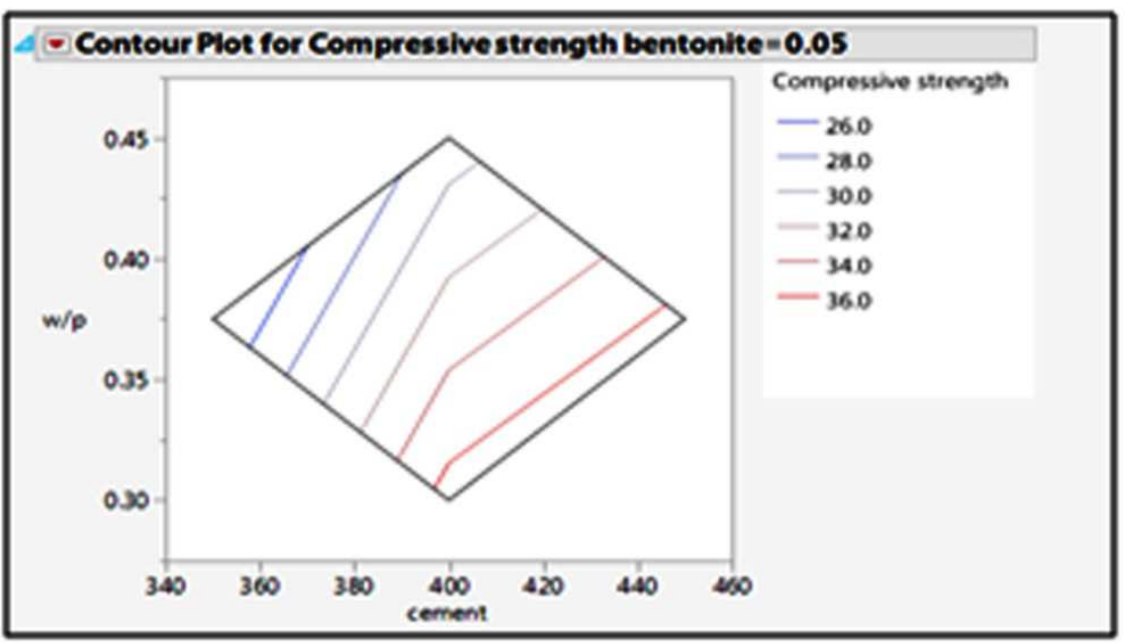

Fig. 2. Contour plot at $5 \%$ bentonite

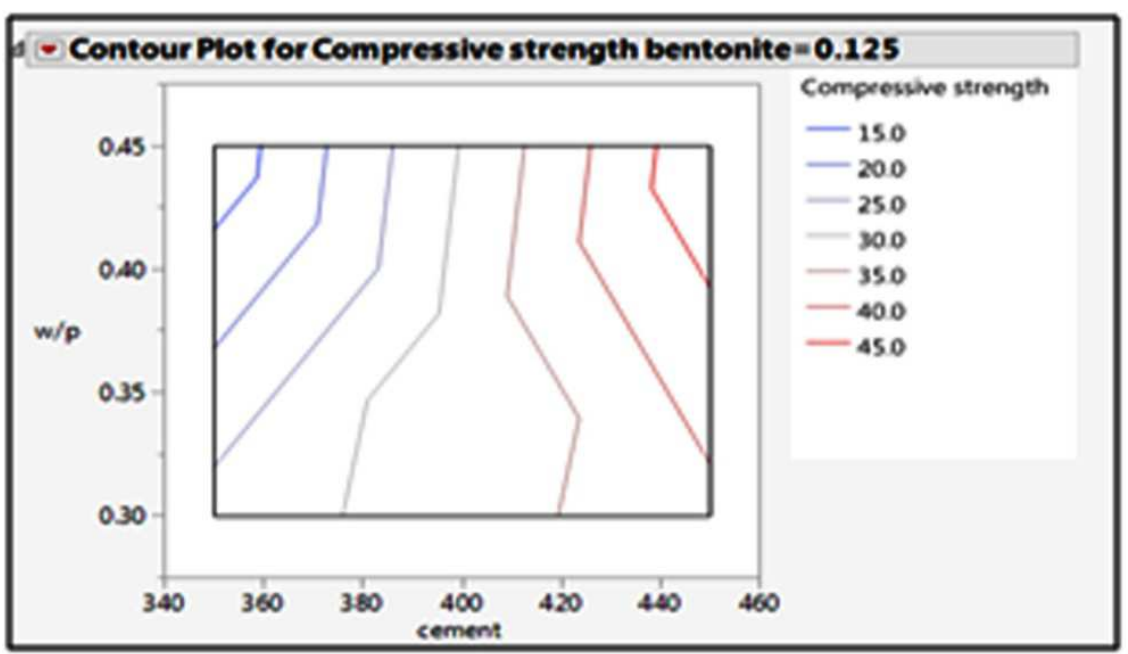

Fig. 3. Contour plot at $12.5 \%$ bentonite 


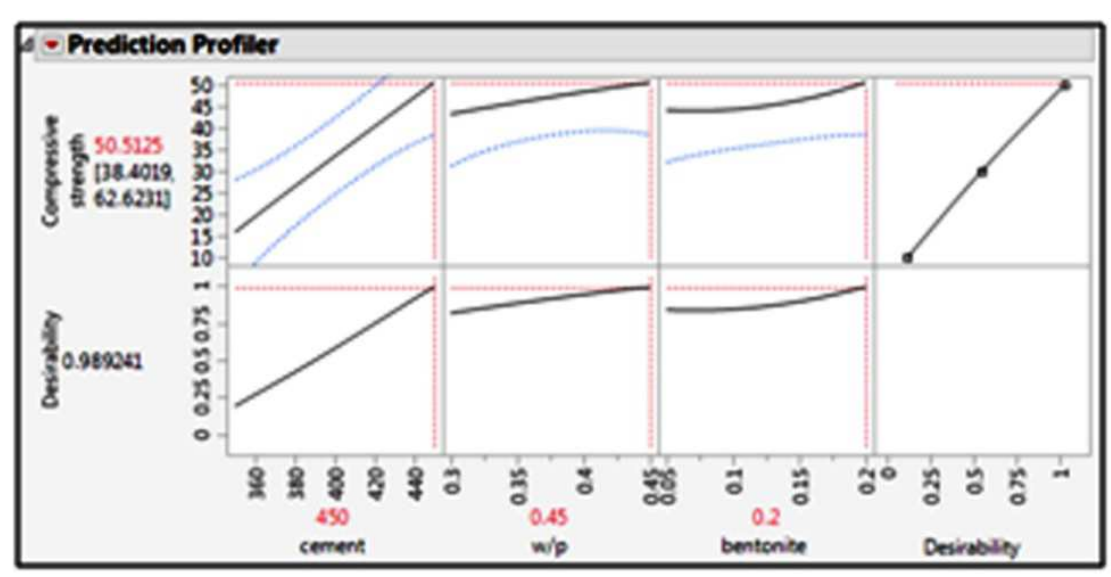

Fig. 4. Prediction profiler for the effect of cement, bentonite and $\mathrm{w} / \mathrm{p}$ ratios on the compressive strength

Table 3. Regression output of full quadratic models for compressive strength at 28 days

\begin{tabular}{|c|c|c|c|c|c|c|c|}
\hline & Estimate & $\begin{array}{l}\text { Standard } \\
\text { Error (SE) }\end{array}$ & t-Ratio & p-value & $\mathrm{R}^{2} \%$ & $\mathrm{R}^{2}$ adj \% & $\mathrm{S}$ \\
\hline \multicolumn{8}{|c|}{ (a) Parameter Estimates Terms } \\
\hline $\mathrm{Fc}_{28}$ & & & & & 93.04 & 80.52 & 3.987 \\
\hline Intercept & 32.0000 & 2.302281 & 13.90 & $<0.001 *$ & & & \\
\hline$C(350,450)$ & 9.7875 & 1.409854 & 6.94 & $0.0010^{*}$ & & & \\
\hline $\mathrm{w} / \mathrm{p}(0.3,0.45)$ & -2.6875 & 1.409854 & -1.91 & 0.1149 & & & \\
\hline bennonite $(0.05,0.2)$ & 2.3750 & 1.409854 & 1.68 & 0.1529 & & & \\
\hline $\mathrm{C}^{*} \mathrm{w} / \mathrm{p}$ & 6.5250 & 1.993834 & 3.27 & $0.0221 *$ & & & \\
\hline $\mathrm{C}^{*}$ bentonite & 1.0000 & 1.993834 & 0.50 & 0.6373 & & & \\
\hline $\mathrm{w} / \mathrm{p}$ *bentonite & -0.2000 & 1.993834 & -0.10 & 0.9240 & & & \\
\hline $\mathrm{C}^{*} \mathrm{C}$ & -0.2375 & 2.075248 & -0.11 & 0.9133 & & & \\
\hline $\mathrm{w} / \mathrm{p} * \mathrm{w} / \mathrm{p}$ & -0.2875 & 2.075248 & -0.14 & 0.8952 & & & \\
\hline bentonite*bentonite & 2.2375 & 2.075248 & 1.08 & 0.3302 & & & \\
\hline \multicolumn{8}{|c|}{ (b) Sorted Parameter Estimates Terms } \\
\hline$C(350,450)$ & 9.7875 & 1.409854 & 6.94 & 0.0010 & & & \\
\hline $\mathrm{C}^{*} \mathrm{w} / \mathrm{p}$ & 6.5250 & 1.993834 & 3.27 & 0.0221 & & & \\
\hline $\mathrm{w} / \mathrm{p}(0.3,0.45)$ & -2.6875 & 1.409854 & -1.91 & 0.1149 & & & \\
\hline bennonite $(0.05,0.2)$ & 2.3750 & 1.409854 & 1.68 & 0.1529 & & & \\
\hline bentonite*bentonite & 2.2375 & 2.075248 & 1.08 & 0.3302 & & & \\
\hline $\mathrm{C}^{*}$ bentonite & 1.0000 & 1.993834 & 0.50 & 0.6373 & & & \\
\hline $\mathrm{w} / \mathrm{p} * \mathrm{w} / \mathrm{p}$ & -0.2875 & 2.075248 & -0.14 & 0.8952 & & & \\
\hline $\mathrm{C}^{*} \mathrm{C}$ & -0.2375 & 2.075248 & -0.11 & 0.9133 & & & \\
\hline $\mathrm{w} / \mathrm{p}$ *bentonite & -0.2000 & 1.993834 & -0.10 & 0.9240 & & & \\
\hline
\end{tabular}

Table 4. Analysis of Variance (ANOVA) of full quadratic models for compressive strength at 28 days

\begin{tabular}{|c|c|c|c|c|c|c|}
\hline $\begin{array}{l}\text { Hardened } \\
\text { SCC test }\end{array}$ & $\begin{array}{l}\text { Source of } \\
\text { Variation } \\
\end{array}$ & $\begin{array}{l}\text { Degree of } \\
\text { Freedom (DF) }\end{array}$ & $\begin{array}{l}\text { Sum of } \\
\text { Square (SS) }\end{array}$ & $\begin{array}{l}\text { Mean } \\
\text { Square (MS) }\end{array}$ & $\mathrm{F}$ & P-value \\
\hline \multirow[t]{6}{*}{$\mathrm{Fc}_{28}$} & Regression & 9 & 1063.529800 & 118.1700 & 7.4314 & \multirow{6}{*}{$\begin{array}{l}\mathrm{P}>\mathrm{F} \\
0.0199 *\end{array}$} \\
\hline & Residual Error & 5 & 79.507500 & 15.9010 & & \\
\hline & C. Total & 14 & 1143.037300 & & & \\
\hline & Lack-of-fit & 3 & 79.507500 & 26.5025 & & \\
\hline & Pure error & 2 & 0.000000 & 0.0000 & & \\
\hline & Total & 5 & 79.507500 & & & \\
\hline
\end{tabular}

A $12.5 \%$ of bentonite mixes shows a higher compressive strength up to $45 \mathrm{Mpa}$ that can be reached by mixing materials that coordinates with the red line above in Fig. 3. W/p content needed to reach maximum compressive strength for the $12.5 \%$ mix is higher than the $5 \%$ mixes and the dominant factor for this increase is due to the high water absorption needed $207 \%$ by its own weight. Lower compressive 
strength may be due to the low percentage of aggregates for some contents.

In Fig. 4, the constituent materials have been locked at $450,0.45,0.2$ and the vertical bars have been moved to determine the proportions of a formulation with lower desirability, but one that still meets the required specifications. The specifications for hardened property of concrete of the concrete $\left(\mathrm{fc}_{28}\right)$ have been easily met:

$$
\text { fc, } 28(\mathrm{MPa})=50.5125 \text {, desirability }=0.989241
$$

Bentonite effect on the compressive strength response are shown in Fig. 4, at the beginning of the curve from left, the curve of bentonite is concaving up from left to right, which tells that when bentonite is increased up to $20 \%$ replacing cement the compressive strength is going to increase.

The effect when replacing more than $20 \%$ of bentonite has not been determined so those results are just convenient for bentonite replacing only from $5 \%$ to $20 \%$. W/p ratio increase the compressive strength when it is lower than 0.375 for $5 \%$ bentonite replacing, but when bentonite quantity increased the vice versa occurs and more $\mathrm{w} / \mathrm{p}$ ratio is required.

\section{Conclusion}

It was included from this research the following points:

- Compressive strength test results showed a variety depending on the materials proportion, mix no. 8 and 9 have a 46 and 49 Mpa respectively and can be categorized of grade M45 which are used for reinforced concrete structure and other mixes compressive strength can be used for suitable works according to the required compressive strength of the required job

- Compressive strength were increased when bentonite replacing cement are increased up to $20 \%$ as shown on the diagram in Fig. 4 and a mix of $450 \mathrm{~kg} / \mathrm{m}^{3}$ of cement, $0.45 \mathrm{w} / \mathrm{p}$ and $20 \%$ of bentonite has been found to be the best mix for reaching a consisted compressive strength above $45 \mathrm{Mpa}$

- Mix no.8 and 9 can be used with reinforcements that require a self-compacting concrete of grade M45 and will give high workability as predicted

\section{Acknowledgement}

The Authors would like to acknowledge all of the engineers they help in implemented this research such as, Khaled Al-Azzeh, MahmoodAbdelrahman, Farah Daradkeh, Anfal Al-Nuaimat, Maha Al-Dahamsheh, Farah Abu-Thawabeh.

\section{Author's Contributions}

All authors participated in all experiments, coordinated the data-analysis and contributed to the writing of the manuscript.

\section{Ethics}

This article is original and contains unpublished material. The corresponding author confirms that all of the other authors have read and approved the manuscript and no ethical issues involved.

\section{References}

Alhasanat, M.B., A.N. Al Qadi, O.A. Al Khashman and A. Dahamsheh, 2016. Scanning electron microscopic evaluation of self-compacting concrete spalling at elevated temperatures. Am. J. Eng. Applied Sci., 9: 119-127. DOI: 10.3844/ajeassp.2016.119.127

Al Qadi, A.N.S., K.N. Mustapha, S. Naganathan and Q.N.S. AL-Kadi, 2013. Development of selfcompacting concrete using contrast constant factorial design. J. King Saud Univ. Eng. Sci., 25: 105-112. DOI: 10.1016/j.jksues.2012.06.002

EFNARC, 2002. Specification and guidelines for selfCompacting Concrete, Association House, 99 West Street, Farnham, Surrey Gu97EN, UK.

Hosterman, J.W. and S.H. Patterson, 1992. Bentonite and fuller's earth resources of the United States. U.S. Geological Survey Professional Paper 1522, United States Government Printing Office, Washingtontn948.B4H67 553.6'l-dc20.

Long, W.J., K.H. Khayat, G. Lemieux, F. Xing and W.L. Wang, 2015. Factorial design approach in proportioning prestressed self-compacting concrete. Materials, 8: 1089-1107. DOI: 10.3390/ma8031089 